\title{
Nobody really knows how to perform endoscopic necrosectomy
}

\author{
Douglas G. Adler, Ali A. Siddiqui ${ }^{1}$ \\ Department of Internal Medicine, Division of Gastroenterology, University of Utah Hospital, Salt Lake City, Utah, ${ }^{1}$ Division \\ of Gastroenterology and Hepatology, Thomas Jefferson University Hospital, Philadelphia, PA, USA
}

The advent of lumen-apposing metal stents (LAMSs) as a tool in endoscopic ultrasound (EUS) has had what can only be called a transformative effect on EUS-guided drainage of pancreatic fluid collections (PFCs) including pseudocysts and, more importantly, walled-off pancreatic necrosis. ${ }^{[1-6]}$ These procedures are being performed at more centers and in much greater numbers than ever before. Older techniques using either double pigtail plastic stents or fully covered metal biliary stents $\left(\right.$ FCSEMSs) ${ }^{[7-9]}$ are largely being phased out given the speed and ease with which LAMS can be placed in patients with PFCs despite the fact that these other devices are also safe and effective. Endoscopic necrosectomy is rapidly replacing surgical necrosectomy in the vast majority of patients as it is minimally invasive, does not require an abdominal incision, and allows debridement and clearance of very large amounts of necrotic tissue. Necrosectomy can be performed in poor operative candidates, patients with ascites, and patients with infected pancreatic necrosis.

One thing that has become clear in the last several years is that, to put it bluntly, nobody really knows how to do endoscopic necrosectomy. This does not

\begin{tabular}{|l|l|}
\hline \multicolumn{2}{|c|}{ Access this article online } \\
\hline Quick Response Code: & Website: \\
\hline & www.eusjournal.com \\
\hline & \\
\hline
\end{tabular}

mean that endoscopic necrosectomy procedures are not being performed safely and with great success around the word. It means that the optimal methods to perform this procedure are not at all clear and there are virtually no comparative studies regarding different techniques to perform these procedures. Endoscopic necrosectomy procedures are carried out in different manners and at different intervals largely based on the personal experience of the interventional endoscopist. In addition, many endoscopists do not manage patients in a uniform manner, further muddying the waters.

Unanswered questions regarding endoscopic necrosectomy include but are not limited to:

1. Should LAMS become the standard of care for the creation of an endoscopic cystenterostomy in patients with pancreatic necrosis?

2. What size of LAMS is optimal in patients with pancreatic necrosis?

3. Is one LAMS enough for all patients with pancreatic necrosis?

4. Should a LAMS be dilated after deployment or allowed to open on its own after placement?

This is an open access article distributed under the terms of the Creative Commons Attribution-NonCommercial-ShareAlike 3.0 License, which allows others to remix, tweak, and build upon the work non-commercially, as long as the author is credited and the new creations are licensed under the identical terms.

How to cite this article: Adler DG, SiddiquiAA. Nobody really knows how to perform endoscopic necrosectomy. Endosc Ultrasound 2017;6:147-8.

\section{Address for correspondence}

Dr. Douglas G. Adler, Department of Gastroenterology and Hepatology, GI Fellowship Program, University of Utah School of Medicine, Huntsman Cancer Center, 30N 1900E 4R118, Salt Lake City, Utah 84132, USA. E-mail: douglas.adler@hsc.utah.edu

Received: 2016-12-20; Accepted: 2016-12-21 
5. Should endoscopic necrosectomy be performed during the same procedure as the creation of the cystenterostomy?

6. What is the optimal interval for repeat endoscopic necrosectomy procedures?

7. Should agents such as diluted hydrogen peroxide be used universally to lavage the PFC cavity in patients with pancreatic necrosis?

8. What endoscopic tools are ideal for retrieving solid necrotic pancreatic tissue?

9. What is the optimal interval for repeat imaging in patients undergoing endoscopic necrosectomy?

10. Which patients should undergo placement of a nasocystic tube (or other tube) so that the PFC cavity can be lavaged?

11. When should LAMS or other stents be removed in patients undergoing endoscopic necrosectomy?

The authors are both very experienced performing endoscopic necrosectomy using LAMS, FCSEMS, and double pigtail stents. Although we are at different institutions and, in many respects, have similar practice patterns overall, our endoscopic necrosectomy techniques differ on several levels. Furthermore, many people have very strong feelings about how these procedures should be performed but do not have any meaningful data to back up their arguments beyond "this is how I do it and it works for me." The authors are, in all fairness, just as guilty of this as anybody as most of our practice patterns have been dictated by our experiences and endoscopic successes (and failures).

Going forward, we would like to see well-constructed studies that randomize patients with pancreatic necrosis to undergo endoscopic necrosectomy through different techniques and using different tools in an attempt to identify ideal techniques and timeframes to produce the next outcome. These studies will be difficult undertakings as it can be difficult for many centers to accumulate a sizeable number of these patients in a year but hopefully these studies can still be undertaken in the near future. It may be the case that there is no optimal manner to perform endoscopic necrosectomy and that several techniques and approaches are equally effective but until the right studies are done, we just cannot know the answers to these important questions.

\section{REFERENCES}

1. Siddiqui AA, Adler DG, Nieto J, et al. EUS-guided drainage of peripancreatic fluid collections and necrosis by using a novel lumen-apposing stent: A large retrospective, multicenter U.S. experience (with videos). Gastrointest Endosc 2016;83:699-707.

2. Sharaiha RZ, Tyberg A, Khashab MA, et al. Endoscopic therapy with lumen-apposing metal stents is safe and effective for patients with pancreatic walled-off necrosis. Clin Gastroenterol Hepatol 2016;14:1797-803.

3. Walter D, Will U, Sanchez-Yague A, et al. A novel lumen-apposing metal stent for endoscopic ultrasound-guided drainage of pancreatic fluid collections: A prospective cohort study. Endoscopy 2015;47:63-7.

4. Bapaye A, Itoi T, Kongkam $\mathrm{P}$, et al. New fully covered large-bore wide-flare removable metal stent for drainage of pancreatic fluid collections: Results of a multicenter study. Dig Endosc 2015;27:499-504.

5. Patil R, Ona MA, Papafragkakis C, et al. Endoscopic ultrasound-guided placement of AXIOS stent for drainage of pancreatic fluid collections. Ann Gastroenterol 2016;29:168-73.

6. Mukai S, Itoi T, Sofuni A, et al. Clinical evaluation of endoscopic ultrasonography-guided drainage using a novel flared-type biflanged metal stent for pancreatic fluid collection. Endosc Ultrasound 2015;4:120-5.

7. Berzosa M, Maheshwari S, Patel KK, et al. Single-step endoscopic ultrasonography-guided drainage of peripancreatic fluid collections with a single self-expandable metal stent and standard linear echoendoscope. Endoscopy 2012;44:543-7.

8. Hocke M, Will U, Gottschalk P, et al. Transgastral retroperitoneal endoscopy in septic patients with pancreatic necrosis or infected pancreatic pseudocysts. Z Gastroenterol 2008;46:1363-8.

9. Lopes CV, Pesenti C, Bories E, et al. Endoscopic ultrasound-guided endoscopic transmural drainage of pancreatic pseudocysts. Arq Gastroenterol 2008;45:17-21. 